\title{
Social Security and Divorce in Japan
}

\author{
$\underline{\text { Sakata, } \mathbf{K}^{1} \text { and C.R. McKenzie }}{ }^{2}$ \\ ${ }^{1}$ Faculty of Economics, Ritsumeikan University \\ Email: ksakata@ec.ritsumei.ac.jp \\ ${ }^{2}$ Faculty of Economics, Keio University, \\ Email: mckenzie@econ.keio.ac.jp
}

\begin{abstract}
The purpose of this paper is to explain variations in the divorce rates across prefectures in Japan over the period 1982 to 2002. This paper examines the various factors which may affect divorce rates including: the effects of the generosity of social welfare; the income of females relative to males; the female employment rate; the vacancy rate; a shift to no-fault divorce, and social stigma. Two key findings of the paper are that the generosity of a particular prefecture in approving Livelihood Protection Benefits and social stigma have statistically negative impacts on the divorce rate.
\end{abstract}

Keywords: Divorce, panel data, welfare 


\section{INTRODUCTION}

Over the past 60 years, family structure in Japan has changed remarkably. One of the important changes relates to the number of divorces and the divorce rate. As in many other developed countries, the Japanese divorce rate has gradually increased.

There is large literature relating to divorce in the United States (for example, Becker (1974), Becker (1985), Becker et al. (1977), Stevenson and Wolfers (2007) and Weiss (1997)). In contrast, despite the attention that has been given to divorce in the Japanese media in recent years, there are very few empirical studies relating to divorce in Japan (Kato (2006a), Sakata and McKenzie (2008), Kato (2006b) and Raymo et al. (2004)).

One of the interesting aspects of Japanese divorces is that there is great deal of diversity in divorce rates across regions and prefectures in Japan. An examination of divorce rates across prefectures over time shows that particular prefectures (for example, Fukuoka and Hokkaido) consistently appear to have high divorce rates (see Table 1).

A key question for economists is whether these regional differences are caused by differences in culture across regions or are caused by differences in economic conditions or a mixture of the two. None of the empirical studies above examined

\begin{tabular}{|r|r|r|r|r|r|r|}
\hline \multicolumn{6}{|c|}{ Table 1: Crude Divorce Rates: Top 5 Prefectures } \\
\hline & \multicolumn{1}{|c|}{1980} & \multicolumn{1}{|c|}{1990} & \multicolumn{1}{|c|}{2000} \\
\hline 1 & Hokkaido & 1.86 & Okinawa & 1.9 & Okinawa & 2.74 \\
\hline 2 & Okinawa & 1.85 & Hokkaido & 1.73 & Osaka & 2.63 \\
\hline 3 & Fukuoka & 1.58 & Fukuoka & 1.61 & Hokkaido & 2.51 \\
\hline 4 & Kochi & 1.53 & Osaka & 1.58 & Fukuoka & 2.42 \\
\hline 5 & Aomori & 1.52 & Tokyo & 1.53 & Miyazaki & 2.32 \\
\hline Source: Vital Statistics & & \multicolumn{5}{l}{} \\
\hline
\end{tabular}
regional differences in divorce rates across Japan.

The purpose of this paper is to examine what causes the regional variations in the divorce rates in Japan. In order to account for such variations, regional differences and variations in the divorce rate over time need to be accounted for. This paper particularly looks into the relationship between the divorce rate, and the income of females relative to males, the female employment rate, business cycle and the accessibility of social security benefits. Unlike the United States, the Japanese legal system is unitary, and, therefore, it is very difficult to find any major legal or systematic differences across prefectures. However, there is a clear difference in the accessibility to some social security benefits across regions.

In the United States, there is a sizeable literature investigating how the social system affects decisions on marital dissolution. Previous studies in this field have examined the extent to which the generosity of the Aid to Families with Dependent Children (AFDC) program has had an impact on marital dissolution, and how social welfare reform in the 1990s affected marriage and divorce. Moffitt (2000) and Bitler et al. (2004) find a statistically significant positive relationship between divorce and social welfare. On the other hand, Blackburn (2003) and Hoffman and Duncan (1995) contend that the effects of AFDC on divorce are limited.

In Japan, it is often claimed that in order to become eligible for Livelihood Protection Benefits (LPB), couples with low income intentionally dissolve their marriage even though they do not have problems with their marriage. However, there is little empirical evidence to support such a claim. This paper seeks to uncover whether regional differences in divorce rates can be partly explained by regional differences in the generosity of accessibility to social security benefits. Two key findings of the paper are that the generosity of a particular prefecture in approving LPB and social stigma have statistically negative impacts on the divorce rate.

Section 2 provides a brief discussion of social security benefits provided by the Livelihood Protection Law (Seikatsu hogoho) in Japan. Section 3 discusses the economic variables that might be expected to affect the divorce rate, while section 4 details the definitions of the variables used and data sources. Estimation results are reported in section 5, and section 6 contains a brief conclusion.

\section{SOCIAL SECURITY SYSTEM}

The legal framework for assistance to the poor and needy in Japan is provided by the national Livelihood Protection Law (Seikatsu Hogoho). Assistance under this Law can be classified into the following eight categories:1) maintenance allowance; 2) education allowance; 3) housing allowance; 4) medical allowance; 5) nursing care allowance; 6) child birth allowance; 7) vocational allowance 8) funeral allowance. One or more of these allowances may be paid to a poor or needy household. 
Table 2: Proportion of Needy Receiving Social Security:

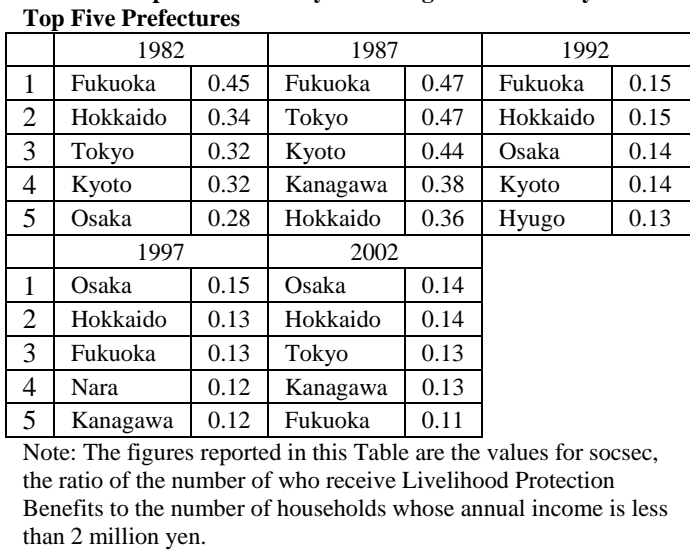

Table 3: Recipients of Livelihood

Protection Benefits by Household Type

\begin{tabular}{lrrr}
\hline & $\mathbf{1 9 9 5}$ & $\mathbf{2 0 0 0}$ & $\mathbf{2 0 0 5}$ \\
\hline Total & 100.0 & 100.0 & 100.0 \\
$\begin{array}{l}\text { Elderly } \\
\text { Households }\end{array}$ & 43.7 & 46.7 & 43.4 \\
$\begin{array}{l}\text { Disabled/Injured } \\
\text { Households }\end{array}$ & 47.8 & 40.3 & 37.4 \\
$\begin{array}{l}\text { Female-headed } \\
\text { Households } \\
\begin{array}{l}\text { Other } \\
\text { Households }\end{array}\end{array}$ & 8.6 & 7.8 & 8.7 \\
\hline Source: Reports on Social Welfare Affairs
\end{tabular}

While this system is a national one, there are reasons for suspecting that there may be significant variations in the generosity of the accessibility to the system across prefectures. Under the present system, $75 \%$ of the cost of livelihood protection assistance is paid for out of the national treasury, with the burden for the remaining $25 \%$ being on the local government body responsible for providing the assistance. In order to reduce its fiscal burden, a local government body has an incentive to strictly control its certification of households that are eligible for livelihood protection. Given that the fiscal position of prefectures differs significantly across Japan, the incentive to certify individuals and provide benefits can also be expected to differ across Japan.

In this paper, the ratio of the number of households with an income under 2 million yen to the number of households who are receiving likelihood protection benefits is used to measure the generosity of the accessibility to social security. For every five years between 1982 and 2002, Table 2 presents details of the five prefectures with the highest ratio of the number of households with an income under 2 million yen to the number of households who are receiving livelihood protection benefits. There is a great deal of variations across the prefectures even though the criteria for granting the livelihood protection benefit are supposed to be the same. Although there are some timing differences between Table 1 and 2, many of the prefectures in the top ten prefectures for divorce rates (Table 1) also appear among the top five prefectures for the generosity of their accessibility to welfare benefits (Table 2).

A cursory examination of the figures in Table 2 indicates that there is a noticeable drop in the ratio after 1987. This is due to a change in the definition of "household" in the Employment Status Survey. In the data for 1992, 1997 and 2002, single households are included in the definition of a "household", while in the data prior to 1992, single households were excluded.

Table 3 provides details of the proportion of female-headed households receiving livelihood protection benefits to the total recipients of livelihood protection benefits. Female-headed households consist of 8 to 9 $\%$ of the total recipients. There are two possible effects of this protection. Since the receipt of the livelihood protection benefit potentially increases out of marriage income for a divorced woman, it is expected that it would increase the probability of divorce. That is, in prefectures where there is a high proportion of households receiving livelihood protection benefits, it is easier for an individual to be certified as being in need of the livelihood protection benefit, and this makes divorce more likely. It should be noted that unlike some of the American social welfare programs discussed in section 1, the livelihood protection benefit is not limited to single mother families. As a result, it could lead to income supplementation in a case where the husband faces a loss of income for some reason. In this case, by raising the household's level of income it could work to prevent marriage dissolutions.

\section{MODEL}

In order to explain variations in divorce rates, the existing literature often controls for increases in the earnings ability of females, variations in the business cycle, and changes in legal changes (Stevenson and Wolfers 2007). This paper estimates the following model: 


$$
\begin{aligned}
& \log \left(\text { mwdiv }_{i t}\right)=\beta_{0}+\beta_{1} \log \left(\operatorname{socsec}_{i t}\right)+\beta_{2} \log \left(\text { relinc }_{i t}\right)+\beta_{3} \log \left(\text { femp }_{6}\right) \\
& +\beta_{4} \log \left(v r_{i t}\right)+\beta_{5} \log \left(\text { pred }_{t}\right)+\beta_{6} \log \left(\text { stigma }_{i t}\right)+\beta_{7} \log \left(\operatorname{loan}_{i t}\right)++\beta_{8} t+\alpha_{i}+e_{i t}
\end{aligned}
$$

where the subscripts $\mathrm{i}$ and $\mathrm{t}$ refer to time $\mathrm{t}$ and prefecture $\mathrm{i}$, respectively; mwdiv is the divorce rate for married women (the number of divorces per 1000 married women); socsec is a variable related to the likelihood of receiving livelihood protection benefits; relinc is the income of females relative to males; femp65 denotes the employment rate of females aged less than 65; $v r$ is the vacancy rate; pred is the estimated probability of victory in a divorce suit where one of the parties is at fault; stigma is a stigma variable, loan is a proxy variable for the time discunt rate of the representative individual in prefecture $\mathrm{i}$ at time $\mathrm{t}$, the time trend is included to take account of changes in social attitudes towards divorce over time, and $e_{i t}$ is a disturbance term. The fixed prefectural effects, $\alpha_{i}$, are included to take account of differences in social attitudes towards divorce that exist across prefectures. The detailed

If the generosity of access to livelihood protection benefits provides an incentive for recipients to divorce then it is expected that $\beta_{1}>0$. Both $\beta_{2}$ and $\beta_{3}$ are expected to be positive as improvements in women's position in the public and private spheres are expected to lead to an increase in the divorce rate. As Sakata and McKenzie (2008) suggest that Japanese divorce rate is counter-cyclical and the legal shift to no-fault divorce increases the divorce rate, it is expected tha $\beta_{4}<0$ and $\beta_{5}>0$. Social stigma can be a strong disincentive to divorce, so that $\beta_{6}<0$ is expected. As explained earlier, the higher a person's time discount rate is the more impulsive her or she is likely to be. An impulsive marriage may lead to a bad matching and therefore, it is expected that $\beta_{7}>0$.

Although this paper attempts to examine the effects of the generosity of livelihood protection benefit certification on divorce, there may be causality in the reverse direction, namely, an increase in the number of divorces may result in an increase in the generosity of livelihood protection benefit certification. As Table 3 indicates, female-headed households consist of 8 to $9 \%$ of the total recipients of LPB on average, which is not a trivial proportion. It is therefore reasonable to take account of the possibility of this reverse causality. In this paper, political variables are used as instruments for socsec. If the criteria for granting livelihood protection benefits vary across the regions, the variation may be caused by differences in political conservatism. In order to allow for the endogeneity of the generosity of accessibility to the welfare system, the share of votes for the Liberal Democratic Party in Lower House election, ldpvr, and for the Communist Party in Lower House elections, commvr, are used as instruments.

\section{DATA}

This paper uses Japanese prefectural panel data for the following years; 1982, 1987, 1992, 1997, and 2002. The data for the number of low income households is categorical, and it is not possible to control for price changes over a long time period. As a result, only data from 1982 was used. Details of variable definitions and sources are summarized in Table 4. In what follows, the logarithm of any of the variables in equation (1) is indicated by the prefix l, so that $\log ($ mdivr) is denoted by lmdivr.

Table 4: Variable Definitions and Data Sources

\begin{tabular}{|l|l|l|}
\hline Variables & \multicolumn{1}{|c|}{ Definitions } & \multicolumn{1}{|c|}{ Sources } \\
\hline mdivr & Divorce rate per 1000 married women & Vital Statistics, Employment Status Survey \\
\hline socsec & $\begin{array}{l}\text { Number of Households receiving Livelihood Protection Benefits/ } \\
\text { Number of households with an annual income below 2 million yen }\end{array}$ & $\begin{array}{l}\text { Reports on Social Welfare Affairs, } \\
\text { Employment Status Survey }\end{array}$ \\
\hline minc & Male annual salary=(monthly salary)*12+annual bonus & Basic Survey on Wage Structure \\
\hline finc & Female annual salary=(monthly salary)*12+annual bonus & Basic Survey on Wage Structure \\
\hline relinc & Relative income=finc/minc & Employment Status Survey \\
\hline femp65 & Employment rate for females aged above 15 and below 65 & Reports on Employment Security Bureau \\
\hline vr & Job vacancy rate: a job offers-to-seekers ratio & Sakata and McKenzie (2008) \\
\hline pred & Predicted probability of winning a model divorce case & Survey on Time Use and Leisure Activities \\
\hline stigma & Participation rate in local improvement activities & National Survey of Family Income and Expenditure \\
\hline loan & Loans (excluding home loans) per household & \multirow{2}{*}{$\begin{array}{l}\text { Japan National Politician Database } \\
\text { http://www.senkyo.janjan.jp/index.html }\end{array}$} \\
\hline ldpvr & $\begin{array}{l}\text { Share of Votes for the Liberal Democratic Party at the Lower } \\
\text { House election }\end{array}$ & \\
\hline commvr & $\begin{array}{l}\text { Share of votes for the Communist Party at the Lower House } \\
\text { election }\end{array}$ & \\
\hline year & Year effect & \\
\hline
\end{tabular}


For the purpose of measuring the generosity of accessibility to social security benefits, socsec is constructed as the ratio of the number of households receiving livelihood protection benefits to the number of households whose annual income is below 2 million yen.

In Sakata and McKenzie (2008), a probit model is used to explain Supreme Court and High Court decisions in divorce suits. Based on recursive estimates of this probit model, the probability of winning a divorce suit after each court case is computed for a 'model' divorce case. Using information about the date of each court case, it is possible to compute a probability of winning a model divorce case in any given year, pred.. The data for pred are taken directly from Sakata and McKenzie (2008). It should be noted that this variable does not vary over prefectures, and in the period being analyzed it contains a strong upward trend.

Link and Phelan (2001) define stigma as "the co-occurrence of its components-labeling, stereotyping, separation, status loss, and discrimination”. There is no regional panel data relating to people's perceptions of divorce. In this paper, rather than measuring stigma directly, a proxy variable that reflects stigma is used. Stigma requires peer pressure. If their ties to the community are very strong, people may not dissolve their marriage because they care about their reputation within their community. Here, the average participation rate for local improvement activities in the Survey on Time Use and Leisure Activities is used as a proxy for stigma.

The model presented in section 3 contains a variable relating to the time discount rate. Obviously data is not available directly on this variable. Ikeda et al. (2005) argue that individuals with low (high) time discount rates are likely to have high (low) savings rates. As an extension of this argument, individuals with low (high) time discount rates are likely to have a small (large) amount of loans outstanding. The amount of loans outstanding per household in a prefecture is used as a proxy for the discount rate in the prefecture. Data on the amount of loans per household in each prefecture was collected from the National Survey of Family Income and Expenditure.

\section{RESULTS}

Descriptive statistics for the variables used in the analysis are presented in Table 5. Initially, equation (1) was estimated by both pooled ordinary least squares (OLS) and by OLS with fixed prefectural effects. Since the null hypothesis that all the coefficients on the fixed prefectural effects are zero is strongly rejected in every case, only the results for the fixed effect case are reported. Tables 6 reports the estimated fixed effect models for equation (1) for OLS and two staged least squares. In the OLS results, the social security variables are statistically significant, but have estimated coefficients that are negative. There are some other consistent findings across these equations. First, the relative income of females has a significant and positive impact on the divorce rate. This is consistent with the idea that as women's economic positions in the household improves, the divorce rate increases. Second, reductions in the job vacancy rate, lead to significant increases in the divorce rate. This finding suggests that in Japan the divorce rate is counter-cyclical. This finding is consistent with the time series evidence in Sakata and McKenzie (2007) for Japan, but is in contrast to the pro-cyclical findings for the United States. Third, the amount of loans per household which is used as a proxy for the time discount rate is always insignificant. Tables 6 reports the estimated fixed effect models for log$\log$ models for OLS and two staged least squares. In the OLS result, the social security variables are statistically significant, but have estimated coefficients that are negative. There are some other consistent findings across these equations. First, the relative income of females has a significant and positive impact on the divorce rate. This is consistent with the idea that as women's economic positions in the household improves, the divorce rate increases. Second, reductions in the job vacancy rate, lead to significant increases in the divorce rate. This finding suggests that in Japan the divorce rate is counter-cyclical. This finding is consistent with the time series evidence in Sakata and McKenzie (2007) for Japan, but is in contrast to the pro-cyclical findings for the United States. Third, the amount of loans per household which is used as a proxy for the time discount rate is always insignificant.

The estimated coefficient of the log of the female employment rate has a negative sign and is significant. This finding is perhaps a little surprising since it is often argued that increases in the work opportunities for non-working married women lead to an increase rather than a decrease in the divorce rate.The estimated coefficient of the stigma variable is negative and significant in all specifications. The sign of this estimated coefficient is consistent with our expectations. Strong community ties appear to play an important role in the divorce decision making process. 
Table 5: Descriptive Statistics

\begin{tabular}{lcrrrr}
\hline \multicolumn{1}{c}{ Variable } & Obs & \multicolumn{1}{c}{ Mean } & Std. Div & \multicolumn{1}{c}{ Min } & \multicolumn{1}{c}{ Max } \\
\hline mwdivr & 235 & 5.929 & 1.853 & 2.973 & 13.241 \\
secsec & 235 & 0.124 & 0.082 & 0.029 & 0.470 \\
relinc & 235 & 0.599 & 0.042 & 0.345 & 0.747 \\
femp65 & 235 & 59.146 & 5.394 & 44.262 & 69.742 \\
vr & 235 & 0.793 & 0.382 & 0.140 & 2.080 \\
pred & 235 & 0.145 & 0.056 & 0.072 & 0.212 \\
stigma & 235 & 21.096 & 5.812 & 6.400 & 38.428 \\
loan & 235 & 373.681 & 182.892 & 87.000 & 965.000 \\
ldpvr & 235 & 49.595 & 12.101 & 15.294 & 80.943 \\
commvr & 235 & 8.630 & 5.071 & 1.445 & 26.422 \\
\hline
\end{tabular}

Table 6: Estimates of the Divorce Equation Assuming Fixed Effects

\begin{tabular}{|c|c|c|c|}
\hline & $\mathrm{OI}$ & & $\overline{\mathrm{LS}}$ \\
\hline & ULS & 2nd Stage & 1st Stage \\
\hline $\begin{array}{c}\text { Dependent } \\
\text { Variable }\end{array}$ & lmwdiv & lmwdiv & lsocsec \\
\hline lsocsec & -0.068 & -0.279 & \\
\hline & $(0.030)^{* *}$ & $(0.131)^{* *}$ & \\
\hline lrelinc & 0.468 & 0.337 & -0.613 \\
\hline & $(0.183)^{* *}$ & $(0.176)^{*}$ & $(0.211)^{* * *}$ \\
\hline lfemp65 & -0.417 & -0.409 & 0.445 \\
\hline & $(0.202)^{* *}$ & $(0.228)^{*}$ & $(0.412)$ \\
\hline $\operatorname{lvr}$ & -0.231 & -0.273 & -0.181 \\
\hline & $(0.021)^{* * *}$ & $(0.035)^{* * *}$ & $(0.044)^{* * *}$ \\
\hline lpred & 0.166 & 0.013 & -0.834 \\
\hline & $(0.036)^{* * *}$ & $(0.101)$ & $(0.069) * * *$ \\
\hline lstigma & -0.202 & -0.319 & -0.560 \\
\hline & $(0.059)^{* * *}$ & $(0.099)^{* * *}$ & $(0.123)^{* * *}$ \\
\hline lloan & -0.025 & -0.058 & -0.135 \\
\hline & $(0.019)$ & $(0.029)^{* *}$ & $(0.035)^{* * *}$ \\
\hline year & 0.012 & 0.009 & -0.017 \\
\hline & $(0.002)^{* * *}$ & $(0.003)^{* * *}$ & $(0.006)^{* * *}$ \\
\hline lldpvr & & & -0.163 \\
\hline & & & $(0.061)^{* * *}$ \\
\hline lcommvr & & & 0.112 \\
\hline & & & $(0.033) * * *$ \\
\hline Constant & -19.068 & -13.452 & 29.955 \\
\hline & $(4.627)^{* * *}$ & $(6.698)^{* *}$ & $(10.915)^{* * *}$ \\
\hline Observations & 235 & 235 & 235 \\
\hline Number of id & 47 & 47 & 47 \\
\hline R-squared & 0.91 & 0.67 & 0.93 \\
\hline Hausman Test & & 0.948 & \\
\hline $\begin{array}{l}\text { Notes: }(1)^{*}, * * \\
10 \%, 5 \% \text { and } 1 \\
\text { (2) The figures } \\
\text { OLS and standa } \\
\text { (3) The figures }\end{array}$ & $\begin{array}{l}\text { *** indicat } \\
\text { nificance le } \\
\text { rentheses a } \\
\text { rors for 2SI } \\
\text { e Hausman }\end{array}$ & $\begin{array}{l}\text { variable is s } \\
\text { l, respectivel } \\
\text { obust standa }\end{array}$ & $\begin{array}{l}\text { nificant at the } \\
\text { errors for }\end{array}$ \\
\hline
\end{tabular}

In order to allow for the endogeneity of the generosity of the accessibility to livelihood protection benefits across prefectures, equation (1) was also estimated using fixed effects two stage least squares, and the results is reported. In Table 6, lldpvr and lcommvr were used as instruments. Fstatistics testing the null hypothesis that all the coefficients (except the constant) are zero in each first stage estimate are all well above 10. The Hausman test is used to test for the endogeneity of the social security benefit variable, and the values reported in Tables 6 suggest that the benefit variable was not endogenous, so that fixed effect OLS is the appropriate estimator.

However, the first stage estimates presented in Tables 6 contain some interesting findings. The estimated coefficient of lldpvr is negative and significantly different from zero, and the estimated coefficients of lcommvr is positive and significantly different from zero. This means that the political conservatism does have an influence on the accessibility to livelihood protection benefits. Furthermore, the estimated coefficient of stigma is negative and significantly different from in all the first stage equations. This suggests that those who are actually eligible for livelihood protection benefits may be reluctant to claim their rights because they fear a loss of reputation in their community. An examination of the evidence for the impact of the expected probability of winning a divorce suit indicates that this variable has a positive and significant coefficient regardless of whether a time trend is included. The results are not influenced by the choice of functional form, and are consistent with Sakata and McKenzie (2008). That is, the Coase theorem does not apply to Japanese divorces, since if the probability of wining a divorce suit increases, marriage are more likely to dissolved.

The difference in the empirical results between Japan and the U. S. in relation to the impact of the social security may be explained by a difference in their respective social security systems, that is, a difference between AFDC and livelihood protection benefits. The American AFDC is particularly targeted at femaleheaded households, while the Japanese livelihood protection benefits are targeted at lower income households. Therefore, it may be argued that when marriage becomes unstable due to a reduction or a loss of income, the livelihood protection benefit reduces the likelihood of divorce via the income support it provides to married households. Even though the conventional wisdom suggests that there is an incentive for married couples to get divorced and to "cheat" the system in order to become eligible for livelihood protection benefits, there is no empirical evidence in this paper to support such a claim.

\section{CONCLUSION}

This paper has examined the various factors which may affect on the divorce rates: the effects of the generosity of accessibility to social welfare; the income of females relative to males; the female employment rate; the vacancy rate; a shift to the no-fault divorce and social stigma. Even though the Livelihood Protection Benefit is a national system, there exist non-trivial variations in take up rates across prefectures. Previous 
studies in the United States suggest that there is positive or no correlation between divorce and the generosity of the social welfare system. In contrast, an increase in the generosity of accessibility to Livelihood Protection Benefits in a particular prefecture has a negative impact on the divorce rate. It is also found that the variations in the generosity of accessibility to Livelihood Protection Benefit across regions are affected by political conservatism and stigma. The results also suggest that some of the regional variation in divorce rates can be partially explained by economic factors such as increases in the income of females relative to males and reductions in the job vacancy rate lead to significant increases in the divorce rate. The finding for the job vacancy rate suggests that in Japan the divorce rate is counter-cyclical. Furthermore, the proxy variable for stigma is significant in explaining regional variations in the Japanese divorce rate. It is often argued that the existence of social security benefits can provide an incentive for married couples to get divorced. The evidence presented in this paper suggests this is not the case for Japan, and this would appear to be consistent with the most recent research for the United States

\section{REFERENCES}

Becker, G.S. (1974), A Theory of Marriage: Part II. Journal of Political Economy, 82(2), S11-S26.

Becker, G.S. (1988), “Family Economics and Macro Behavior. American Economic Review, 64(2), 317-319.

Becker, G.S., E.M. Landes, and R.T. Michael (1977), An Economic Analysis of Marital Instability. Journal of Political Economy, 85(6), 1141-1188.

Bitler, M.P., J.B. Gelbach, H.W. Hoynes, and M. Zavodny (2004), The Impact of Welfare Reform on Marriage and Divorce. Demography, 41(2), 213-236.

Blackburn, M.L. (2003), The Effects of the Welfare System on Martial Dissolution. Journal of Population Economics, 16(3), 477-500.

Hoffman, S.D. and G.J. Duncan (1995), The Effect of Incomes, Wages, and AFDC Benefits on Marital Disruption. Journal of Human Resources, 30(1), 19-41.

Ikeda, S., F. Ohtake, and Y. Tsutsui (2005), Jikan Waribikiritsu: Keizai Jikken to Ankeeto ni yoru Bunseki (Time Discount Rates: An Analysis Based on Economic Experiments and Questionaire Surveys). Discussion Paper No. 74, COE Discussion Paper, Osaka University.

Kato, A. (2006a), Time Series Analysis of Divorce and the Labour Market (Rikon to Rodo Shijyo no Jikeiretsu Bunseki). in Demographic Research of Trends, the Background and Propospects of Divorce and Remarriage as Causes of the Low Birth Rate (Shoshika no Yoin toshiteno Rikon Saikon no Doko, Haikei oyobi Mitoshi ni Kansuru Jinnkougakuteki Kenkyu). pp. 85-97, National Institute Of Population and Social Security Research, Tokyo (in Japanese).

Kato, A. (2006b) Family Demography of Marriage and Divorce (Kekkon to Rikon no Kazoku Jinkogaku )” in Demographic Research of Trends, the Background and Propospects of Divorce and Remarriage as Causes of the Low Birth Rate Shoshika no Yoin toshiteno Rikon Saikon no Doko, Haikei oyobi Mitoshi ni Kansuru Jinnkougakuteki Kenkyu. pp. 99-112, National Institute of Population and Social Security Research, Tokyo (in Japanese).

Link, B.G. and J.C. Phelan. (2001), Conceptualizing Stigma Annual Review of Sociology, 27(1), 363-385.

Moffitt, R.A. (1983), An Economic Model of Welfare Stigma. American Economic Review, 73(5), 10231035.

Moffitt, R.A. (2000), Welfare Benefits and Female Headship in U.S. Time Series. American Economic Review, 90(2), 373-377.

Raymo, J., M. Iwazawa, and L. Bumpass (2004), Marital Dissolution in Japan: Recent Trends and Patterns. Demographic Research, 11(14), 395-420.

Sakata, K. and C.R. McKenzie. (2008) A Time Series Analysis of the Divorce Rate in Japan Using a Precedent-Based Index. Mathematics and Computers in Simulation.

Stevenson, B. and J. Wolfers. (2007), Marriage and Divorce: Changes and their Driving Forces. Journal of Economic Perspectives, 21(2), 27-52.

Weiss, Y. (1997), The Formation and Dissolution of Families: Why Marry? Who Marries Whom? And What Happens Upon Divorce? in Rosenzweig, M. and Stark, O. eds., Handbook of Population and Family Economics, North-Holland, Amsterdam. 